\title{
DES/RE/ESCREVENDO A HISTÓRIA DOS MEIOS DE COMUNICAÇÃO: quatro contribuições a partir das Arqueologias das mídias
}

\author{
Marcio Telles ${ }^{1}$
}

Resumo: Como contraproposta à historiografia tradicional das mídias, as Arqueologias das mídias almejam descobrir histórias alternativas à narrativa positivista, criando ruídos nas certezas quanto ao progresso tecnológico. São muitas as maneiras de colocar tal projeto em prática, todos tendo como centralidade quatro processos de escrita: des-escrever, descrever, escrever e re-escrever as histórias dos meios. Neste artigo, foco em quatro abordagens e retiro de cada uma delas uma tese central: Kittler/Parikka (materialidade), Zelinski (variação), Kluitenberg (imaginário) e Ernst (arqueografia), que contribuem para os estudos de mídia, mas são, a meu ver, ainda insuficientes para lidar com os processos comunicacionais.

Palavras-chave: Arqueologia das Mídias; História das Mídias; Materialidades da Comunicação; Metodologia; Teorias de Mídia Alemãs.

Abstract: Against traditional media historiography, media archaeology seeks to discover alternative histories to the usual narrative, questioning our confidence on technological progress. There are many ways of employing this project into practice, all of which have as their core four writing processes: unwriting, describing, writing and rewriting media histories. In this paper, I will focus on four approaches, discussing for each one a central thesis: Kittler/Parikka (materiality), Zelinski (variation), Kluitenberg (imaginary) and Ernst (archaeography). Each one contributes to media studies in general but, in my opinion, are still insufficient to engage with the scholarship on communicational processes.

Keywords: Media archaeology; Media history; Materialities of Communication; Media Studies; German Media Theory.

\section{Introdução}

Suponhamos que, quando olhamos para a história dos meios de comunicação, tendamos a exaltar a inexorabilidade do progresso técnico, apontando para um futuro brilhante, onde uma mídia não é mais do que um aprimoramento da anterior, todas convergindo em direção da máquina multimídia definitiva, o computador. Essa subjugação da tecnologia a uma narrativa milenarista parece querer nos dizer que "tudo sempre estava ao redor, apenas numa forma menos elaborada [...] A passagem dos séculos apenas aprimora e aperfeiçoa as grandes ideias arcaicas” (ZIELINSKI, 2006, p. 17). Tal narrativa progressista é encampada pelos grandes fabricantes de tecnologias de mídias e os enormes conglomerados de conteúdo (cada vez mais indistintos), como Google, Apple, Amazon, Facebook e Microsoft, que tendem a inscrever suas inovações no ápice desta cadeia evolutiva, dando "a

${ }^{1}$ Doutorando e mestre em Comunicação e Informação pelo Programa de Pós-Graduação em Comunicação e Informação da UFRGS, com período sanduíche realizado na Winchester School of Art, University of Southampton, Reino Unido, com bolsa Capes do Programa de Doutorado Sanduíche no Exterior. 
impressão de um progresso que acaba em seus ambientes tecnológicos corporativos" (PARIKKA, 2017, p. 202).

De modo geral, o que tem sido chamado de "Arqueologia das mídias" é uma maneira de desorganizar a linha temporal progressiva da "historiografia tradicional" comunicação, quiçá mesmo virá-la de ponta-cabeça. Nas palavras do teórico alemão Siegfried Zielinski (2006, p. 21): “A história da mídia não é o resultado do avanço previsível e necessário de um aparato primitivo para um aparato complexo. O atual estado da arte não necessariamente representa o melhor estado possível”. De forma programática, os mídiaarqueólogos almejam, em vez de focar na narrativa progressista, "serem capazes de descobrir variações individuais e pontos de virada qualitativos" (NATALE, 2012, p. 525, tradução minha).

No Brasil, o termo tem ganhado tração nos últimos anos, com a publicação de um dossiê sobre Arqueologia das mídias na revista do Programa em Tecnologia da Inteligência e Design Digital da PUC-SP (cf. ALY, 2016), um livro coletânea (MELLO; CONTER, 2017), além do trabalho de autores que expressamente se identificam com a abordagem, como Fischer (2015), Silveira (2016) e Nunes (2017). Esse aumento no interesse das abordagens arqueológicas não é sem tempo, já que o próprio Siegfried Zielinski ministrou o curso “Arqueologia das Mídias" no PEPG em Comunicação e Semiótica da PUC-SP em agosto de 2001 (MACHADO, 2002), com seu livro Deep History of Media posteriormente recebendo no Brasil o título do curso (ZIELINSKI, 2006).

Popularização do termo à parte, o fato é que o Brasil, se comparado com a inserção cada vez maior da abordagem nos países de língua inglesa, ainda continua alheio à Arqueologia das mídias. Pensando nisso, o objetivo deste artigo é apresentar quatro correntes de teóricos que se rotulam como "arqueólogos" das mídias, discutindo as especificidades de cada abordagem a partir de um núcleo de operações em comum. Não se trata apenas de uma revisão bibliográfica: também pretendo identificar o que há de comum às quatro abordagens; identificar como elas resolvem aspectos diferentes de um mesmo problema (daí a proposta do uso do termo no plural) e, nas considerações finais, contrapor as Arqueologias das mídias aos

\footnotetext{
${ }^{2}$ Estou apontando entre aspas, e tomando por "suposições" (no início do texto) "(bastante) gerais" (um pouco adiante) o espantalho que erijem os teóricos das Arqueologias das mídias das "historiografias tradicionais", como sendo uma estratégia retórica para se diferenciarem (cf. Sobretudo HUHTAMO; PARIKKA, 2011; PARIKKA, 2012). Não quer dizer que sejam verdadeiras nem que eu concorde com elas. É preciso reconhecer, agora que as Arqueologias já não são mais novidades (pelo menos em inglês), que falta uma distinção mais clara entre estas e a História das Mídias e Nova História, bem como um maior diálogo com a produção destas últimas.
} 
estudos sobre os processos comunicacionais, compreendendo que Comunicação e Mídias, dois objetos de interesse do campo, não podem ser tomados um pelo outro.

\section{Operadores arqueológicos}

De modo (bastante) geral, podemos dizer que a historiografia das mídias sofre de (a) uma ênfase teleológica e progressista que toma o novo pelo velho e vice-versa e (b) a valorização das respostas institucionalizadas sobre as mídias (de jornais, arquivos governamentais, etc.) em detrimento dos pontos de vista individuais, não-sistematizados e caóticos. Em ambos os casos, o resultado é a separação entre os diversos níveis de fenômenos cristalizados nas mídias e seu consequente alijamento das percepções a respeito destes meios: por exemplo, se tomarmos a popularização da TV nos anos do pós-guerra apenas pelas revistas especializadas, pelos meios oficiais, pelas políticas públicas, pelos modos de produção de conteúdo e pelos balanços de marketing, esconderemos níveis que talvez tenham tanto a dizer quanto este acontecimento do que os outros. Mais ainda, esconderemos as histórias alternativas das televisões que poderiam ter sido, mas não foram: como mostra William Uricchio (2008) na Alemanha do entreguerras, havia ao menos quatro projetos concorrentes para o desenvolvimento da tecnologia televisiva, cada qual levaria à realização de um meio de comunicação diferente ${ }^{3}$.

Do ponto de vista das Arqueologias, a história da televisão como uma narrativa linear passando do rádio (telecomunicação) ou da fotografia/cinema (comunicação visual), chegando ao Netflix e ao YouTube, não estaria completa se não pudesse decompô-la na materialidade dos instrumentos tecnológicos, das superfícies de visualização e das técnicas culturais de assistência televisiva, assim hackeando (STRAUVEN, 2015) a historiografia costumeira, enfatizando as rupturas e as conexões entre períodos históricos distintos. É neste momento que as Arqueologias das mídias tentam se opor mais claramente à História das Mídias "tradicional”: as primeiras são conjuntos de ferramentas capazes de criar distúrbios na segunda, revelando seu lado “inconsciente” e “monstruoso". Para Wanda Strauven (2015), é

\footnotetext{
${ }^{3}$ Além do aparelho doméstico que acabou vingando (apoiada pela indústria dos eletrônicos de consumo, inspirada no Volksempfänger, que tentou lançar também kits televisivos para serem montados em caso), havia o projeto defendido pelo Ministério de Propaganda de Goebbells de criar salas de TV públicas; outro projeto contava com a TV como um meio de comunicação de duas vias (o "videofone"), defendido pelos Correios alemães; ainda outro, apresentado pelo Ministério da Defesa Aérea, via na TV uma ferramenta de reconhecimento de linhas inimigas e de telepresença, como guia visual para bombas, torpedos e mísseis no formato de minicâmeras acopladas aos projéteis e controladas remotamente. Não seriam estas "pré-" ou "quase-"televisões também relevantes para pensar a TV?
} 
justamente a criação de ruídos o objetivo da empreitada arqueológica: é preciso que exista um hack da História maiúscula, assim criando histórias "menores".

Este "hackeamento" da História se dá a partir de quatro operações de escritura teórica: as Arqueologias 1) des-escrevem a historiografia de viés progressista ao procurar por pontos de fissura dentro da narrativa convencional e/ou canônica; 2) escrevem histórias alternativas das mídias ao incorporar pioneiros, tendências ou tecnologias esquecidos, ou mesmo improváveis, em suas genealogias; 3) descrevem, às vezes perigando a tecnofilia, universos de tecnologias esquecidas, mortas ou apenas imaginadas; 4) reescrevem a história das mídias e dos ambientes (tecno)culturais nas quais elas se encontram, inserindo-lhes ruídos, de forma que eles permaneçam críticos, abertos e instáveis.

Seria, porém, o suficiente para chamar tal projeto de "pensamento", "método" ou “disciplina”? A discussão do que é a arqueologia das mídias transpassa quase todos os textos de autorreflexão teórica. Huhtamo e Parikka (2011, p. 2, ênfase e tradução minhas), por exemplo, advogam que as Arqueologias das mídias não são nem uma disciplina, nem apenas um approach, mas "um conjunto de abordagens estreitamente relacionadas". Todavia, como nota criticamente um resenhista da obra dos escandinavos, Huhtamo e Parikka desejam fazer da escorregadia indefinição de sua "(in)disciplina" a força dela, encorajando a interdisciplinaridade e a experimentação (POTTS, 2013) - ou, como já dito, o hack.

Gostaria de propor as Arqueologias das mídias tanto como um "conjunto de abordagens" quanto um modo geral de pensar a história dos meios de comunicação. Creio ser possível advogar pela bipartição entre núcleo firme, acima descrito (o problema identificado e as operações), e um cinturão de hipóteses, microteorias e inclinações metodológicas que dele partem, cada uma almejando colocar em prática a des/re/escrita da História. Gostaria de abordar ao menos quatro delas neste artigo: uma de inclinação materialista, vinculada a Friederich Kittler e desenvolvida por Jussi Parikka; outra de ordem discursiva: o estudo das mídias imaginárias de Eric Kluitenberg; uma variante anárquica que faz proliferar mídias e genealogias, ligada a Zielinski; e uma última de caráter epistemológico e ontológico, que indaga as condições de escritura do próprio arquivo que investiga, projeto de Wolfgang Ernst.

\section{Kittler, Parikka e as Materialidades}

De muitas formas, Friedrich Kittler pode ser considerado o pai das Arqueologias das mídias (PARIKKA, 2012). Seu pressuposto central de que toda mídia é um sistema de 
inscrição, processamento e transmissão e que cada "rede discursiva" centrada numa ecologia de mídia é também um novo regime de sensação e possibilidade de ação é a abertura para o questionamento sobre a centralidade da mídia nos contextos históricos e sociais. A Arqueologia da mídia, para Kittler, constitui-se vis-à-vis à ênfase na importância do tecnológico como sistema de inscrição, relacionando o arqueológico (as condições de conhecimento) ao genealógico (a história inscrita em vários materiais). Kittler tenta cruzar a arqueologia foucaultiana das condições de conhecimento com o interesse mcluhaniano em como a mídia forma nossas habilidades sensoriais e cognitivas (KITTLER, 1999, 2016).

É por este viés que se deve ler a afirmação de Kittler: "mídia determina nossa situação, da qual - em prol ou apesar disso - merece uma descrição" (1999, p. xxxix, tradução minha). O alemão está interessado em como constelações midiáticas mudam historicamente, "modulando" pensamentos, sensações, percepções e memórias. Tais modulações inscrevemse sempre sobre uma superfície determinada, o corpo. Desde a psicofísica do século XIX, o interesse na rapidez e lerdeza nas respostas a estímulos exteriores está na base das investigações sobre a tecnocultura midiática dos séculos XX e XXI. Questões sobre como humanos sincronizam estímulos múltiplos de fontes de sentidos diversos; como criam a ilusão de imagens estáticas para colocá-las em movimento para seus olhos e de como as várias vibrações por segundo que a agulha de um fonógrafo registra se tornam centrais para a investigação arqueológica de viés kittleriano, pois são capazes de mapear as possibilidades e os limites do corpo humano, apontando novas direções para a pedagogia midiática.

Daí que o vetor de movimento do arqueólogo não é (apenas) para trás no tempo, mas para dentro da máquina. A busca não é somente por descendentes históricos, mas também ocorre em termos de infraestruturas computacionais, seus circuitos e transistores, pois a mídia é a própria condição do conhecimento (KITTLER, 1999) de uma determinada época, e também de percepção, sensação, memória, experiência, tempo (PARIKKA, 2012). É por isso que o objeto das Arqueologias das mídias kittleriana não é as pessoas, os discursos ou as narrativas, mas a própria tecnologia de mídia, sempre abordada através de seus "artefatos concretos, soluções de design e camadas tecnológicas variadas que vão do hardware para processos de software, [pois] cada qual à sua maneira atu[a] na circulação de tempo e memória" (HERTZ; PARIKKA, 2016, p. 105).

É nesse sentido que se pode compreender outra afirmação excêntrica de Friedrich Kittler: "não há software” (2013). Para o teórico alemão, aquilo que se aceita 
corriqueiramente como "conteúdo" da mídia existe somente na memória do computador: a imaterialidade dos softwares está entrelaçada à realidade material do hardware. Aí que, em qualquer regime midiático, as formas de expressão são indissociáveis de suas formas de conteúdo. No pensamento kittleriano mais maduro, seu interesse se volta para as condições epistêmicas da escrita, de um ponto de vista ontológico em que a técnica da escrita e o ato de escrever são duplamente articulados, escrevendo sua própria condição de escritura (daí seu interesse na invenção do alfabeto). Kittler aponta para a necessidade de repensar noções metafísicas de forma e matéria na era da informática, assim como prestar atenção em esquemas de engenharia que são verdadeiras ontologias: caso da estrutura de John Von Neumann, onde o par aristotélico forma/substância é substituído por comandos, endereços e dados; ou a ontologia tradutória de Alan Turing (KITTLER, 2013). Assim,

...[essa] perspectiva da arqueologia das mídias, portanto, gostaria de literalmente entrar na caixa preta, abri-la e examinar seu funcionamento físico, numa perspectiva mais informada pela física e engenharia do que pela hermenêutica cultural e a semântica. No limite, isso significaria a exclusão de qualquer interesse não apenas no [...] conteúdo ou nas práticas [...] mas até no próprio software [...] (GODDARD, 2015, p. 11, tradução minha).

Por esse ponto de vista, a abordagem da arqueologia das mídias se limitaria ao estudo do hardware e suas matérias, materiais, infraestruturas físicas e sistemas operacionais físicoquímicos. Esse programa de pesquisa é posto em operação pelo pesquisador finlandês Jussi Parikka, cujas investigações se dão em camadas, passando das ressonâncias biológicas no design das tecnologias de mídia (vírus, enxames, insetos), até lixo eletrônico, fósseis de mídias defuntas (HERTZ; PARIKKA, 2016) e os processos sígnicos dos minerais raros (PARIKKA, 2015). Para ele, é possível reescrever a historiografia das mídias a partir de seus materiais, já que cada agenciamento específico possui affordances que possibilitam diferentes maneiras de comunicar, armazenar, transmitir e processar a informação (PARIKKA; FEIGELFELD, 2015), assim contrariando uma das principais críticas à obra kittleriana - o de abstrair das mídias as dimensões política, econômica e (infra)estrutural das quais fazem parte, com exceção do complexo industrial-militar (cf. a crítica de GODDARD, 2015). Como Parikka (2015) tem reforçado em diversas de suas incursões arqueológicas, o poder geopolítico opera também ao nível infraestrutural dos cabos de telecomunicação.

Kittler não se reconhecia como um "arqueólogo das mídias" por que sua investigação nem sempre era histórica; porém era "metaforicamente" arqueológica no sentido em que via a 
própria tecnologia por camadas e procurava perfurá-la para descobrir suas entranhas. Por um lado, podemos afirmar que esse vetor sincrônico foi herdado por todas as vertentes de arqueologias de mídia, fazendo de Kittler seu principal teórico. Por outro lado, uma perfuração de camadas em busca de vestígios do passado refere-se também à disciplina irmã da arqueologia, a paleontologia - e é de um paleontólogo que Zielinski retira a inspiração para seu trabalho.

\section{Zielinski e a Variantologia}

Baseando-se na obra do paleontólogo americano Stephen Jay Gould, o filósofo alemão Siegfried Zielinski prega por um tempo paleontológico da mídia, insistindo que o desenvolvimento da mídia não é progressivo, indo do mais primitivo ao mais complexo, mas cíclico. Isso inverte a ideia de excelência: excelente não é aquilo que é mais "tecnologicamente avançado", mas o mais diverso, já que a excelência “deve ser medida com referência aos eventos de diversificação e à difusão da diversidade” (ZIELINSKI, 2006, p. 19). Parafraseando Bertolt Brecht, "ordem é sinal de carência, e não de abundância" (apud ZIELINSKI, 2006, p. 43).

Assim se torna objetivo da variantologia, um dos dois termos pelo qual Zielinski chama sua abordagem, "revelar [a] grande diversidade, que, ou se perdeu devido ao modo genealógico de observar as coisas, ou foi ignorado por essa visão” (2006, p. 22). Ou seja, descobrir variações heterogêneas que revelem o dinamismo da sedimentação arqueológica e, ao mesmo tempo, "celebrar" tal heterogeneidade em sua tensão com o presente (e com o futuro). Para tanto, volta-se às

[...] situações do passado em que as coisas e as condições ainda estavam num estado de fluxo, quando as opções de desenvolvimento em diversas direções ainda estavam muito abertas, quando o futuro era passível de ser concebido como sustentador de diversas possibilidades (ZIELINSKI, 2006, p. 25).

Tais momentos - ou "janelas" - precedem movimentos de padronização que eliminam a diversidade em prol de uma tecnologia que, mais tarde, será incorporada à narrativa de viés progressista. Essas janelas são o que Zielinski (2006, p. 48) chama de "foco de atração", foci “onde se experimentaram possíveis direções para o desenvolvimento [das tecnologias de mídia] e ocorreram possíveis mudanças de paradigma". A maneira de chegar a eles é manter a atenção aberta atrás dos objetos e dos inventores que "cintilam". Um tipo de predisposição 
investigativa que o autor irá taxar de anarquista, despreocupada com os limites disciplinares. É isso que faz com que Zielinski, na segunda introdução a seu Arqueologia da mídia (2006), rotule sua abordagem de "anarqueológica". A anarqueologia leva o conceito de ruptura para o centro da própria Arqueologia das mídias, forçando as rachaduras teóricas e disciplinares que as outras abordagens apenas sugerem, e assim se recusando a identificar um conjunto de objetos e métodos de análise padronizados e definidos a priori. Logo, a pesquisa anarqueológica "deve reservar a opção de sair pela tangente, de ser desenfreadamente entusiástica, e ao mesmo tempo de criticar o que deve ser criticado" (ZIELINSKI, 2006, p. 43).

O anarqueológo deve aceitar os riscos de pesquisas infrutíferas e estar aberto ao inesperado. Como observa Goddard (2015), isto faz com que Zielinski esteja mais interessado nos "perdedores", aqueles inventores cujas invenções ou jamais se concretizaram ou não foram massivamente adotadas, completando sua intenção de inversão historiográfica: sendo seu "lugar de morada" o possível, a realidade "torna-se uma sombra em comparação" (ZIELINSKI, 2006, p. 44).

\section{Kluitenberg e o imaginário das mídias}

A interação entre possibilidade e realidade lança sombras sobre outra área de interesse das Arqueologias das mídias: o estudo das "mídias imaginárias" (imaginary media). Sugerido pelo teórico holandês Eric Kluitenberg e tendo seu texto seminal na coletânea por ele editada The Book of Imaginary Media (2006), o programa da arqueologia das mídias imaginárias almeja uma "escavação" dos sonhos da cultura tecnomidiática, buscando pelos desejos, anseios e expectativas que direcionam o desenvolvimento tecnológico.

Simone Natale e Gabriele Balbi (2014), dois teóricos italianos que se engajam no programa de Kluitenberg, apontam que o lócus de análise deste tipo de arqueologia das mídias encontra-se no “[...] reino do fantástico, [buscando por] especulações, narrativas imaginárias, predições e outras formas de fantasias a respeito das tecnologias de mídia" (NATALE; BALBI, 2014, p. 203, tradução minha). Desse ponto de vista, as fantasias midiáticas são importantes para a teoria por auxiliar a compreensão das expectativas nutridas ao longo das fases do desenvolvimento tecnológico. Em comparação com o desenvolvimento real da tecnologia, calha que as expectativas são deixadas de lado, reservando-se como mola propulsora dos desenvolvimentos seguintes. 
Assim, pode-se dizer que as mídias imaginárias mediam desejos impossíveis, sendo, por consequência, máquinas impossíveis (KLUITENBERG, 2011). Porém, se o monocórdio de Fludd e a mídia universal de Athanasius Kircher permaneceram apenas no reino dos conceitos e dos modelos (ZIELINSKI, 2006), as máquinas "impossíveis" de Kluitenberg foram, ao menos tentativamente, produzidas. Que tenham sido incompletamente realizadas é a questão. Como não são criações fictícias, as mediações dessas máquinas com o desejo e a fantasia produzem expectativas que excedem o que elas são capazes de fazer (de realizar). Como toda tecnologia produz um imaginário de si e está inserida em um contexto de imaginários que jogam decisivamente para sua realização, as mídias qua imaginários sempre excedem as mídias qua aparatos, articulando um complexo campo de significação e determinação que borra os limites entre o real e o imaginário tecnológicos.

O imaginário excedente à atualidade torna o reino das soluções imaginárias o campo em que as mídias realizam todo seu potencial. Por um lado, como toda mídia é também imaginária, significa dizer que nenhuma mídia jamais está concluída; ela sempre reserva um lado onde suas contradições continuam operando indefinidamente - é este lado "fantasioso" que será buscado por esse tipo de abordagem. Assim, toda tecnologia de mídia está sempre em falta em relação às suas qualidades imaginárias, mesmo quando suas formações realizadas entram em novas relações e excedem a imaginação que as colocou em operação.

Kluitenberg corre o risco de recair em um platonismo vulgar, já que a Mídia Perfeita e suas diversas iterações possíveis (as versões de mídias atuais cujas fantasias foram exauridas) - é impossível de ser encontrada senão no imaginário. É de se "imaginar" que a Mídia Perfeita, aquela que atende a todos os desejos (im)possíveis, é a eliminação de todo processo de mediação, a analogia perfeita - Deus. É, portanto, uma mídia Ideal no sentido mais platônico de eidolon. O próprio autor não descarta essa leitura:

Porque os desejos impossíveis nunca podem ser plenamente realizados ou satisfeitos, as mídias imaginárias excedem o domínio dos aparelhos (máquinas de mídia realizadas) e suas "histórias". Elas articulam um campo altamente complexo de significação e determinação que tende a desfocar os limites entre os imaginários tecnológicos e o efetivo desenvolvimento tecnológico. (KLUITENBERG, 2011, p. 48, tradução minha).

Consequentemente, um dos principais problemas na teoria de Kluitenberg é que ela não considera a mídia de uma perspectiva dinâmica. Como existe uma mídia Ideal da qual sua realização é uma degeneração da Ideia, Kluitenberg ignora que toda tecnologia, ao longo de sua "vida", continuamente muda de significado, audiência, práticas, usos, técnica e até de 
imaginário (NATALE; BALBI, 2014). Não obstante, é possível resumir a proposta de uma arqueologia do imaginário das mídias (e das mídias imaginárias), nos seguintes postulados: 1) a imaginação é um aspecto inerente às tecnologias e seus usos ao longo de toda vida de uma mídia; 2) o imaginário é um motor potente da inovação tecnológica e midiática, produtora de possibilidades a serem exploradas por inventores, artistas e empreendedores; 3) o estudo dos imaginários da mídia oferece uma porta de entrada para contextos culturais específicos e os desejos que subjazem as práticas mediais; 4) o estudo dos imaginários das mídias evita, como aponta já o nome, o aspecto material das mídias, preferindo focar-se em seus discursos.

O foco no discurso, aliás, é o que permite a Kluitenberg (2011) afirmar que sua abordagem das Arqueologias das mídias é a mais próxima do projeto original da arqueologia do conhecimento de Foucault.

\section{Ernst: da arqueologia à arqueografia}

Ao mesmo tempo radicalizando o posicionamento de Kittler e criticando as demais abordagens anteriores, o teórico alemão Wolfgang Ernst aponta que as Arqueologias das mídias têm seu ponto cego no próprio meio técnico e em suas diferentes maneiras de armazenar, processar e manipular o tempo: ou seja, são as mídias - e não o pesquisador - as verdadeiras "arqueólogas" do passado.

Para Ernst, as tecnologias de mídia não podem ser confundidas com seu conteúdo; elas devem ser pensadas como "entidades não discursivas" (2016a, p. 44) pertencentes a regimes temporais distintos, mesmo que não exista diferença no funcionamento do aparato técnico agora e outrora: um rádio da Segunda Guerra ainda é operacional hoje por que a frequência em que recebe uma transmissão não foi alterada. Ou seja, quando o mesmo Volksempfänger, o rádio utilizado no entreguerras na Alemanha para receber os discursos de Hitler é ligado em 2018 e se ouve através dele não a voz colérica do ditador alemão, mas cantoras pop contemporâneas como Beyoncé ou Rihanna, ocorre "um curto circuito mídia-arqueológico entre tempos, de outra forma, historicamente separados com clareza" (ERNST, 2016a, p. 44). É o meio de comunicação que junta dois estratos distintos de tempo: o ontem com o hoje.

$\mathrm{Na}$ conceituação de Ernst (2016b), as mídias são "equiprimordiais": toda operação midiática ocorre no presente (quando o aparelho está ligado) e, portanto, não faz distinção entre antes e agora: os sinais técnicos sempre ocorrem no presente, borrando a distinção entre história (o domínio humano) e a atualidade (o domínio técnico). Da mesma maneira, não faz 
diferença se os sinais técnicos veiculados por um meio de comunicação se originam no passado (gravação, etc.) ou no presente (ao vivo, etc.), pois permanecem temporalmente indistintos em sua processualidade (ou seja, são equiprimordiais). A ideia de um passado "histórico" é assim alheia às mídias, já que imagens e sons do passado são sempre "presentes" (re-apresentados) quando re-produzidos.

Logo, se o The Dead Media Project de Bruce Sterling (1995) preocupava-se com a nostalgia das mídias mortas - as lembranças, memórias, relatos e afetos que tínhamos delas Wolfgang Ernst se propõe como uma espécie de "re-animator", pois "é somente no momento de sua articulação ativa do tempo que as mídias estão vivas e se tornam arqueológicas conectando transhistoricamente o tempo" (PARIKKA, 2011, p. 63, tradução minha). Este trânsito entre passado e presente faz da própria mídia em sua concretude uma "mídia do tempo", ligado não só o que foi com o que é, mas também a memória cultural à memória tecnológica.

As Arqueologias das mídias se convertem, nas mãos e sob o olhar de Ernst, em uma "ferramenta analítica", um método capaz de compreender as diferentes configurações epistêmicas (maquínicas) engendradas pelas mídias em sua dimensão fenomenológica, da experiência de estar de fronte a um aparelho técnico comunicante, sempre no presente. Portanto, o principal conceito operatório de Ernst (2016b) é o de time-critical media, cujas diversas dimensões não cabem aqui debater, ainda que seja importante pontuar que, como as temporalidades (e as tempo-realidades) dos meios técnicos "perturbam" as noções abstratas do tempo humano, assim separando o tempo maquínico do tempo cultural/social, elas só podem ser compreendidas através da análise técnica dos sinais em oposição aos "signos culturais". Ou, mais claramente: a análise de como os meios de comunicação operam no eixo temporal desconsidera o conteúdo e foca nos processos usados para criar/manipular o tempo.

Radicalizando o não-humanismo de Kittler, Ernst propõe que é a própria Arqueologia das mídias uma maneira distinta (técnica) de escrever a história, apropriadamente rebatizando-a de Arqueografia das mídias,

[...] interessada em procedimentos e eventos que não são históricos (ou seja, narráveis) mas entretanto consistem-se de "mudanças autóctones" (Foucault) no âmbito das máquinas e seus símbolos. Palavras e coisas acontecem dentro da máquina (computadores) como lógica e hardware. O olhar mídia-arqueológico, consequentemente, é imanente à máquina. Seres humanos, ao terem criado máquinas lógicas, criaram uma descontinuidade com seu próprio regime cultural (ERNST, 2016a, p. 58). 
Ernst (2016a, p. 59) compreende o "olhar" arqueográfico como "enumerativo ao invés de narrativo, descritivo ao invés de discursivo, infraestrutural ao invés de sociológico". Ou seja, mais importa pensar o rádio no nível do campo eletromagnético do que na semântica da voz falada. Tais instâncias "não-hermenêuticas" são o registro mais próximo do Real que as mídias são capazes de chegar, já que “[h]istória e tempo são gravados 'objetivamente' nos objetos materiais da mídia" (PARIKKA, 2011, p. 60, tradução minha). Assim toda mídia "é um tipo diferente de 'arquivo', não histórico-cultural, mas tecnológico-cultural, outro tipo de informação sobre o real" (ERNST, 2016a, p. 57).

Esse é o ímpeto por trás de seu media lab, o Media Archaeology Fundus (MAF) localizado no Instituto de Musicologia e Estudos de Mídia da Universidade Humboldt de Berlim, cuja missão é coletar tecnologias de mídia para auxiliar no ensino de sua epistemologia de mídia, ofertando um espaço em que práxis e teoria se fundem como complementares. Como afirma o autor, "as teorias de mídia só funcionam quando são testadas contra as evidências do hardware" (ERNST, 2013, p. 60, tradução e ênfase meus ${ }^{4}$ ).

Em suma, o projeto de Ernst advoga que, mais do que compreender as Arqueologias das mídias como a busca por indícios e narrativas, elas devem ser compreendidas a partir da processualidade material das tecnologias de mídia, ou seja, através das infraestruturas material e lógica que operam e sua consequente tempo-manipulação. O mídia-arqueólogo, por conseguinte, se torna menos um historiador e mais um engenheiro.

\section{Considerações finais}

Gostaria de retomar alguns dos principais pontos desta discussão sobre as Arqueologias das mídias começando pelo nome: singular e/ou plural. Para o caso do singular, apontei que existe uma preocupação comum aos diversos teóricos de contrariar a historiografia "tradicional" sobre meios de comunicação, vista por eles como excessivamente progressista; disto resulta que todos advogam quatro tipos de operadores básicos: des-escrita da história comum; escrita de histórias alternativas; descrição dos aparatos técnicos; reescrita de um ambiente histórico aberto e instável. A maneira como se responde ao problema e se engaja com estas operações leva ao "conjunto de abordagens" descrito neste artigo, que

\footnotetext{
4"Media theories work only when being tested against hard(ware) evidence". Natália Aly traduziu a mesma passagem como "As teorias da mídia só funcionam quando são testadas contra as evidências dos equipamentos" (ERNST, 2016a, p. 48). O jogo de palavras que o autor faz é de difícil tradução, porém, preferi por enfatizar o termo hardware ao invés de equipamento, muito asséptico para o que Ernst propõe.
} 
podem ser resumidas em quatro teses: 1) Escavar não apenas para trás, mas para baixo (e para dentro) das tecnologias (Kittler e Parikka); 2) Buscar pelos momentos de maior variedade na história de uma tecnologia (Zielinski); 3) Observar os imaginários atrelados às diversas fases de vida de uma mídia (Kluitenberg); 4) Testar as teorias sobre mídias do passado contra a concretude dos hardwares (Ernst).

Penso que estas quatro teses podem ser tomadas como ponto de partida para uma investigação a respeito da materialidade dos meios de comunicação, pois cercam esse objeto de estudo por vários lados. Todavia, a meu ver, elas não são capazes de lidar com aquilo que mais interesse aos pesquisadores brasileiros: a relação entre as tecnologias de comunicação e os processos comunicacionais. Quer dizer, elas ainda não são suficientes para descrever como experimentamos a Comunicação em diversos contextos históricos. Haveria, por exemplo, possibilidades distintas de comunicação para a sociedade entre uma televisão materialmente mecânica, uma elétrica analógica e outra digital e dispersa? Certamente que sim. Como passar então de uma dimensão material/midiática a uma comunicacional/processual na pesquisa em Comunicação? Tal é o desafio teórico ao qual tenho me dedicado nos últimos anos.

Dentro desta breve crítica, a abordagem de Ernst não é apenas particularmente problemática, como nociva, pois des-historiciza a pesquisa em comunicação: entre Hitler e Beyoncé, mesmo se ambos forem escutados no mesmo aparelho, há mundos de diferenças para além das dimensões tecnológica e material. Neste sentido, acredito ser pertinente a observação de Martino de que

[a]creditamos que a comunicação é um tipo de 'continente' inalterável, e que 'somente' os meios e os conteúdos [...] mudam, quando na realidade seria preciso admitir que a própria comunicação está sujeita a transformações significativas ao longo do tempo (MARTINO, 2017, p. 126).

Penso que, no futuro, os acadêmicos que se engajarem com as Arqueologias das mídias precisarão responder a esta provocação. Por ora, ressalto que tal crítica não invalida as contribuições que as Arqueologias das mídias têm para ofertar. Como um conjunto de abordagens bastante jovem, sua potência talvez esteja mesmo em sua indefinição - cabe a nós, pesquisadores, decidir o que fazer com elas. 


\section{Referências}

ALY, Natália. Dossiê: Arqueologia das mídias. Teccogs: Revista Digital de Tecnologias Cognitivas, TIDD | PUC-SP, São Paulo, n. 14, p. 21-40, jul-dez. 2016.

ERNST, Wolfgang. Digital Memory and the Archive. Minneapolis e Londres: University of Minnesota Press, 2013.

; EMERSON, Lori. Archives, Materiality and the "Agency of the Machine": An Interview with Wolfgang Ernst. (2013). Disponível em: https://blogs.loc.gov/thesignal/2013/02/archives-materiality-and-agency-of-the-machine-aninterview-with-wolfgang-ernst/. Acessado em 11 de julho de 2017.

Arqueografia da mídia: Método e máquina versus história e narrativa da mídia.

Teccogs: Revista Digital de Tecnologias Cognitivas, TIDD | PUC-SP, São Paulo, n.14, p. 42-62, jul-dez. 2016a. Tradução de Natália Aly.

Chronopoetics: the temporal being and operativity of technological media.

Londres, Nova Iorque: Rowman \& Littlefield, 2016b.

FISCHER, Gustavo D. "The Restart Page": observações sobre construtos de memória no terreno da web. Anais do XXXVIII Congresso Brasileiro de Ciências da Comunicação, Rio de Janeiro, 2015.

GODDARD, Michael. Opening up the black boxes: Media archaeology, 'anarchaeology' and media materiality. New Media \& Society, v.17, n.11, p. 1-16, 2015.

HERTZ, Garnet; PARIKKA, Jussi. Mídia zumbi: desvio de circuito da arqueologia da mídia para um método de arte. Teccogs: Revista Digital de Tecnologias Cognitivas, TIDD | PUCSP, São Paulo, n.14, p. 93-113, jul-dez. 2016. Tradução de Alessandro Mancio de Camargo.

HUHTAMO, Erkki; PARIKKA, Jussi. Introduction: an archaeology of media archaeology. In: HUHTAMO, Erkki; PARIKKA, Jussi (Orgs.). Media Archaeology: approaches, applications, and implications. Berkeley, Los Angeles, Londres: University of California Press, 2011, p. 1-21.

KITTLER, Friedrich. Discourse Networks: 1800-1900. Stanford, EUA: Stanford University Press, 1990.

. Gramophone, Film, Typewriter. Stanford, EUA: Stanford University Press, 1999.

The Truth of the Technological World: essays on the Genealogy of Presence.

Stanford, California: Stanford University Press, 2013.

. Mídias Ópticas: curso em Berlim, 1999. Trad. Markus Hediger. Rio de Janeiro:

Contraponto, 2016. 
KLUITENBERG, Eric. The Book of Imaginary Media: Excavating the Dream of the Ultimate Communication Medium, Roterdão: NAi, com Amsterdão: De Balie, 2006.

On the Archaeology of Imaginary Media. In: HUHTAMO, Erkki; PARIKKA, Jussi (Orgs.). Media Archaeology: approaches, applications, and implications. Berkeley, Los Angeles, Londres: University of California Press, 2011, p. 48-69.

MACHADO, Irene. O que há de novo no século XX? Sobre o curso "Arqueologia das mídias". Galáxia, n. 3, 2002, p. 201-206.

MELLO, Jamer Guterres de; CONTER, Marcelo B. (Orgs). A(na)rqueologias das mídias. Curitiba: Appris, 2017.

NATALE, Simone. Understanding Media Archaeology. Canadian Journal of Communication, v.37, p. 523-527, 2012.

; BALBI, Gabriele. Media and the Imaginary in History. Media History, v.20, n.2, p. 203-218, 2014.

NUNES, Caroline Govari. Arqueologia do rock gaúcho: uma perspectiva inicial teóricometodológica com foco nas carreiras de Edu K e Júpiter Maçã. Temática, Ano XIII, n. 11, Novembro/2017, p.1-17.

PARIKKA, Jussi. Operative Media Archaeology: Wolfgang Ernst's materialist media diagrammatics. Theory, Culture \& Society. SAGE, Los Angeles, Londres, Nova Deli e Singapura, v.28, n.5, p. 52-74, 2011.

What is media archeology? Cambridge, EUA: Polity Press, 2012.

Archival Media Theory: An Introduction to Wolfgang Ernst's Media Archaeology. In: ERNST, Wolfgang. Digital Memory and the Archive. Minneapolis, Londres: University of Minnesota Press, 2013, p. 1-22,

A Geology of Media. Minneapolis, EUA: University of Minnesota Press, 2015.

; FEIGELFELD, Paul. Media Archaeology Out of Nature: An Interview with Jussi Parikka. e-flux journal, n.62, p. 1-14, fevereiro de 2015.

- Arqueologia da Mídia: interrogando o novo na artemídia. Trad. Marcio Telles e Luiza Müller. Intexto, Porto Alegre, UFRGS, n. 39, p. 201-214, maio/ago. 2017.

POTTS, John. Jussi Parikka, What is Media Archaeology? \& Erkki Huhtamo and Jussi Parikka (eds), Media Archaeology: approaches, applications and implications; Resenha de.

Screen, v.54, n.1, p. 113-117, 2013.

SILVEIRA, Fabrício L. Música pop e guerra aérea. Anais do XXXIX Congresso Brasileiro de Ciências da Comunicação, São Paulo, 2016. 
STERLING, Bruce. The Dead Media Project. 1995. Disponível em http://www.deadmedia.org/. Último acesso: 13 de julho de 2017.

STRAUVEN, Wanda. The (Noisy) Praxis of Media Archaeology. In: BELTRAME, Alberto; FIDOTTA, Giuseppe; MARIANI, Andrea (Orgs.). At the Borders of (Film) History:

Temporality, Archaeology, Theories: XXI Convegno internazionale di studi sul cinema. Udine, Itália: Forum, 2015, p. 33-42.

URICCHIO, William. Television's First Seventy-five Years: The Interpretive Flexibility of a Medium in Transition. In: KOLKER, Robert (Org.). The Oxford Handbook of Film and Media Studies. Oxford, Inglaterra: Oxford University Press, 2008, p. 286-305.

ZIELINSKI, Siegfired. Arqueologia da mídia: em busca do tempo remoto das técnicas do ver e do ouvir. Trad. Carlos D. Szlak. São Paulo: Annablumme, 2006. 